This article was published in The Journal of Adhesion, 90, 80-88, 2014

http://dx.doi.org/10.1080/00218464.2013.784693

\title{
Evaluation of Bonding Performance of Amino Polymers Using ABES
}

\author{
N. A. $\operatorname{COSTA}^{1,2,3}$, J. PEREIRA ${ }^{1,3}$, J. FERRA ${ }^{2}$, P. CRUZ ${ }^{2}$, J. MARTINS ${ }^{1,4}$, \\ F. D. MAGALHÃES ${ }^{1}$, A. MENDES ${ }^{1}$, and L. H. CARVALHO ${ }^{1,4}$
}

${ }^{1}$ LEPAE, Laboratory for Process, Environmental and Energy Engineering, Faculty of

Engineering, University of Porto, Porto, Portugal

${ }^{2}$ EuroResinas - Indústrias Químicas, Sines Portugal

${ }^{3}$ ARCP, Competence Network in Polymers Association, Porto, Portugal

${ }^{4}$ DEMad, Department of Wood Engineering, Polytechnic Institute of Viseu, Viseu, Portugal

In this paper, the use of Automated Bonding Evaluation System (ABES) for evaluation of bonding strength of wood adhesives is presented. A simple reactive model is proposed, which considers the phenomena involved during resin cure: formation of wood-resin-wood bonds. In the present study, experimental data of a standard urea-formaldehyde (UF) resin using different catalysts, phosphoric acid and ammonium sulphate, are presented and discussed. The proposed can be applied to wood adhesives, namely formaldehyde-based resins under different temperatures. The model fits well to experimental data, presenting high determination coefficient values.

KEYWORDS Adhesion by chemical bonding; Adhesives for wood; Mechanical properties of adhesives; Polymers; Wood

\section{INTRODUCTION}

Wood is one of the most popular building materials in the world, but prior to the emergence of wood-based panels, it had some drawbacks that made it undesirable for many projects. Woodbased panel is a general term for a variety of the different board products made of wood, which have an impressive range of engineering properties [1]. The most common wood-based panels (WBP) are particleboard (PB) and medium density fibreboard (MDF) bonded with an adhesive, usually urea-formaldehyde (UF) or melamine-urea-formaldehyde (MUF) resins [2]. WBP have a positive impact on the rule of carbon storage, due to the high incorporation of recycled wood in their composition [2]. However, boards produced with recycled wood present higher formaldehyde emissions [3]. Due to the recommendation for formaldehyde reclassification as "carcinogenic to humans" by the International Agency for Research on Cancer (IARC) published in 2006 [4], the concern about formaldehyde issues has been increased, and new regulations 
have been imposed in order to reduce formaldehyde emissions from wood-based products. Facing the new guidelines, substantial efforts to develop and provide products with low emission levels were made by WBP manufacturers [5,6]. Formaldehyde release during the boards in service is caused not only by the hydrolysis of formaldehyde bonds in the polymeric structure of adhesive, but also by the liberation of free formaldehyde $[7,8]$. The most common strategies to reduce formaldehyde emission are: reduction of formaldehyde to amino groups molar ratio, development and optimization of new synthesis protocols, and the use of formaldehyde scavengers [9]. In the last few years, several studies have been focused on synthesis protocols of formaldehyde-based adhesives $[10,11]$ as well as on the incorporation of reinforcing agents, such as sucrose [12] and melamine [13]. Several studies on formaldehyde scavengers were also developed with success [6,14-16], allowing them to attain emissions at solid wood level [6]. Few studies can be found regarding UF resins. Gunnells and Griffin [17] presented a catalytic system based on buffer solutions, but its higher price and lower reactivity did not convince industrial producers. Ammonium sulphate and ammonium nitrate are the most common catalysts, also called latent catalysts because, at higher temperatures, they react with formaldehyde forming sulphuric or nitric acid, decreasing $\mathrm{pH}$ environment and promoting the cure reaction. However, these catalysts form hexamine as a by-product [8]. Costa et al. [18] showed that hexamine contributes to formaldehyde release during the lifetime of panels. Boards produced by these authors using phosphoric acid as a catalyst (which not produce hexamine as by-product) presented lower formaldehyde emissions than boards produced with ammonium sulphate, when stored under forceful conditions. These results motivate the study for catalytic systems for UF resins.

Several techniques for the characterization of wood adhesives are available, such as gel permeation chromatography (GPC) and high-performance liquid chromatography (HPLC) [19], as well as spectroscopic techniques such as infrared (IR) [20], near infrared (NIR) [12,21,22], nuclear magnetic resonance (NMR) $[20,23,24]$ and Raman [25], among other techniques. Unfortunately, the attempts that have been made with these techniques in order to correlate the characterization data (e.g., quantity of functional groups) and the mechanical performance of the adhesive (board internal bond strength) did not attain robust relationships. During the hot-pressing process of a WBP, it can be distinguished between the chemical curing (building up of the three-dimensional network) of the thermosetting adhesive and the mechanical forming of the bonding strength between wood and adhesive [26]. Differential scanning calorimetry (DSC) gives useful information about the adhesive "chemical cure" [27,28] allowing the estimation of the degree of chemical curing. Mechanical curing in the sense of the increase in cohesive bond strength can be monitored by thermomechanical analysis (TMA), dynamic mechanical analysis (DMA), or Automated Bonding Evaluation Sys-tem (ABES) [29]. ABES [30] is a powerful and versatile technique for evaluation of "mechanical cure." This apparatus is based on a single lap shear test, but the joint is usually small $(60$ to $100 \mathrm{~mm} 2$ ) and the pressing conditions such as temperature, pressing time, as well as pressure can be adjusted. The overlapped strips could be also cooled before testing in shear mode, making ABES a suitable apparatus for the determination of shear strength as a function of resin type, catalytic system, resin load, cure temperature, time, substrate, etc. in WBP research [26,31-36]. Nevertheless, ABES is a destructive test providing only one data point per test, and it cannot be used for continuous in situ processes. Studies considering adhesive characterization and bonding strength evaluation using ABES usually consider the adhesive as a mixture of resin and catalyst. In this work, ABES apparatus are used to characterize UF resins. Curing temperature, resin load, and different catalytic systems were studied (latent catalyst: ammonium sulphate and poliprotic 
acid: phosphoric acid). Innovation of the model proposed is the reduction of the number of trials needed for the characterization, which allows the preservation of adhesive properties during all the experiment. A mathematical model is proposed to predict the bond strength development, a possible kin-etic model is also presented, and the kinetic constants for UF resin in the presence of different catalytic systems are calculated.

\section{MATERIAL AND METHODS}

\subsection{Materials}

UF resin with a F/U molar ratio of 1.07 was provided by EuroResinas - Indústrias Químicas, S. A. (Sines, Portugal). This resin was previously characterized in terms of bond strength in WBP and formaldehyde content in a previous work [18]. Beech (Fagussylvatica L.) veneer strips for ABES tests were supplied by Sonae Indústria, PCDM S. A. (Mangualde, Portugal). Catalysts used were provided by Euroresinas (ammonium sulphate) and purchased from Panreac (phosphoric acid $85 \%$ solution, analytical grade).

\subsection{Methods}

Tests with ABES apparatus (Fig. 1) were made using beech veneers strips $0.5 \mathrm{~mm}$ thick, $20 \mathrm{~mm}$ wide, and $117 \mathrm{~mm}$ in length. For each test, two veneer strips were glued together with an overlap of $5 \mathrm{~mm}$.

Beech strips were stored at a controlled temperature $\left(25^{\circ} \mathrm{C}\right)$ and relative humidity $(65 \%)$ prior cutting. Prior to testing, strips were prepared using a die cutter supplied by Adhesive Evaluation Systems (Corvallis, Oregon). Adherent pairs were mounted in the system with an overlapping area of $100 \mathrm{~mm}^{2}$.
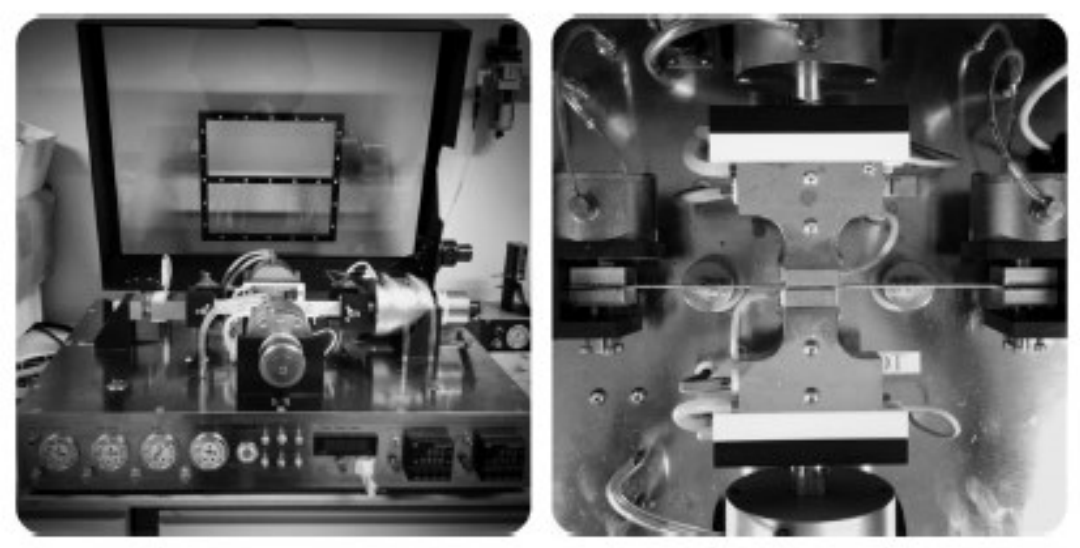

Figure 1. ABES equipment: a) front view and b) top view

\section{RESULTS AND DISCUSSION}

\subsection{Effect of Resin Load on Shear Strength}

$A B E S$ tries to simulate the bond strength development that occurs inside the mat during the hotpressing of a WBP. The shear strength of a glue joint depends on the number of bonds formed between wood and the thermo-setting resin. These bonds are formed during the resin cure. 
Therefore, resin cure depends on the temperature attained inside the mat, while the maximum shear strength is dependent on the number of wood-resin-wood $(w-r-w)$ bonds. The number of $w-r-w$ is intrinsically related with the amount of resin per area (resin load). Figure 2a shows the evolution of shear strength with increasing of temperature for a resin load of $80 \mathrm{~g} / \mathrm{m}^{2}$. It is visible that, as expected, shear strength increases faster at higher temperatures. However, it is observed that the maximum shear strength was reached after 350 seconds at $95^{\circ} \mathrm{C}$, while at $85^{\circ} \mathrm{C}$ it is only reached after 600 seconds of pressing time. Figure $2 \mathrm{~b}$ shows the shear strength according to the resin load for a temperature of $115^{\circ} \mathrm{C}$ using $3 \mathrm{wt} . \%$ of ammonium sulfate as a catalyst and pressed during 350 seconds. Although for these tests, species with micro-structural uniformity and a certain level of hardness and density are recommended (as in the case of beech), small differences in shear strength could be related to the inherent variability of wood. Despite the variability of raw materials, differences observed in the maximum shear strength could be related to the thermal damage kinetics of adhesive bonds $[8,36]$.
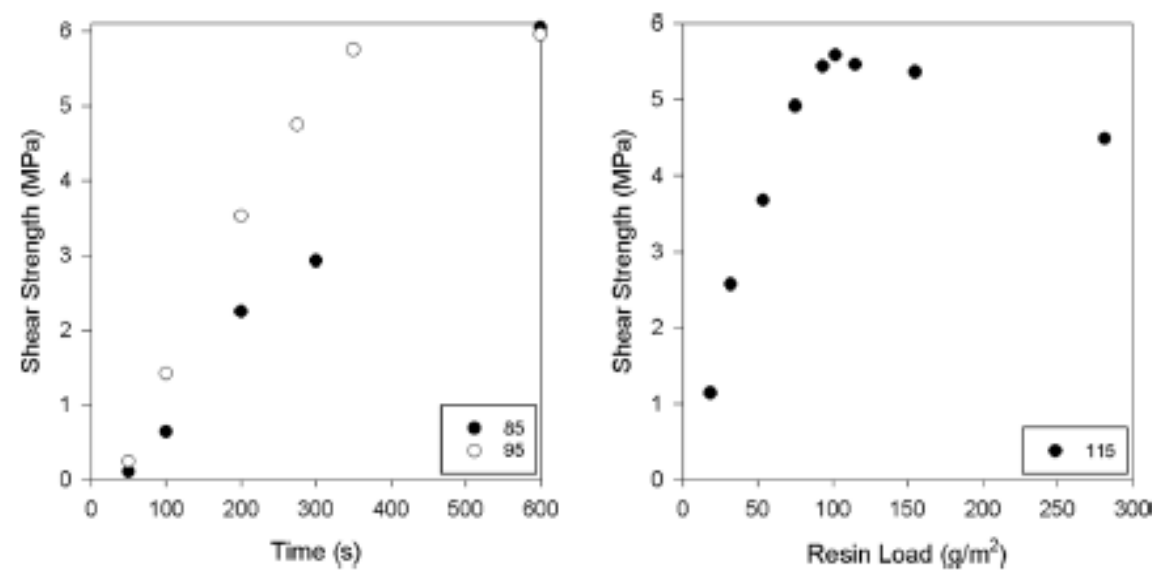

Figure 2. Shear strength of a UF resin measured in ABES: $a$ ) influence of temperature and $b$ ) influence of resin load (temperatures shown are in Celsius degrees).

\subsection{Models to Predict Shear Strength of ABES Data}

\section{MATHEMATICAL MODEL}

ABES apparatus is easy to use; however, a careful treatment of data is needed in order to obtain a complete characterization of an adhesive, considering the curing rate, as a function of temperature, as well as the determination of gel time and kinetic constant. Equation (1) represents a simple empirical model, based on a hyperbolic tangent function, where shear strength $(\alpha)$ is function of time $(t)$, that can be used to describe the experimental curves. In the argument of the hyperbolic function there is a time constant, which is the time needed to reach half of the maximum shear strength, called $t_{0}$, which is related to the gel time of the resin. The variable $\lambda$ is called dynamic cure constant and could be associated with the reaction kinetic constant.

$$
\sigma=\frac{\sigma_{\max }}{1+A}\left(A+\operatorname{tanb}\left[\frac{t-t_{0}}{\lambda}\right]\right), \text { where } A=\operatorname{tanb}\left(\frac{t_{0}}{\lambda}\right)
$$

This mathematical model can be easily linearized to obtain the values of 
these two parameters ( $t_{\circ}$ and $\lambda$ ) by Eq. (2). Maximum shear strength $\left(\alpha_{\max }\right)$ is defined as the maximum value obtained in ABES tests.

\section{KINETIC MODEL}

The previous model can be proven to be a representation of a simple kinetic model based on the assumption of two reactions: an apparent first order reaction $\left(k_{1}\right)$ and an apparent second order reaction $\left(\mathrm{k}_{2}\right)$. The proposed model intends to be a simple kinetic description of the bond formation mechanism, considering the reaction of resin with two molecules of formaldehyde and consequent bonding to wood strips $(w-r-w)$. The second reaction represents the reaction of two molecules of formaldehyde with the $(w-r-w)$ linkage, forming a "double bond linkage" $(w=r=w)$, forming a stronger structure.

Equation 2 describes the rate of formation of the wood-resin-wood bonds. $\mathrm{C}$ is proportional to $\alpha$ and is related to the concentration of formed wood-resin bonds.

$$
\frac{\mathrm{dC}}{\mathrm{dt}}=\mathrm{k}_{1} \mathrm{C}_{\mathrm{F}}+\mathrm{k}_{2} \mathrm{CC}_{\mathrm{F}} \text {, where } \mathrm{C}_{\mathrm{F}}=\mathrm{C}_{0}^{*}-\mathrm{C} \text { and } \sigma \alpha \mathrm{C} \text {. }
$$

Figure 3 shows ABES experimental data of a standard UF resin evaluated under different temperatures (between 85 and 115]C) using different catalysts: phosphoric acid (Fig. 3a) and ammonium sulfate (Fig. 3b). When ammonium sulphate is used at $105^{\circ} \mathrm{C}$, a significant deviation from the model is observed. The fact that this deviation is only observed for this latent catalyst, close to the water boiling temperature, may indicate that the ammonium sulfate equilibrium reaction with formaldehyde to form sulfuric acid is displaced to the left side by excess water.
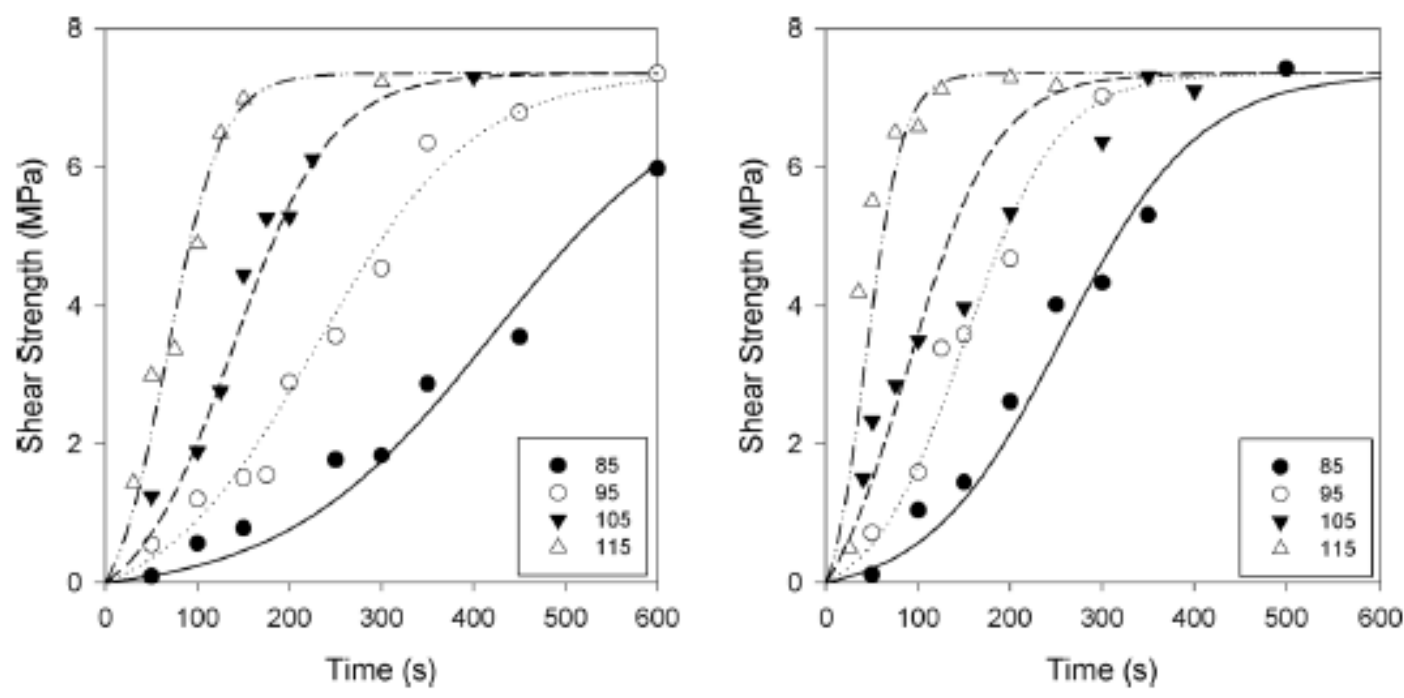

Figure 3. Experimental data and reactive model of UF resin catalyzed with: a) phosphoric acid and b) ammonium sulfate (temperatures shown are in Celsius degrees).

Table 1 shows the values of model parameters obtained by fitting the proposed model to the experimental data. The maximum shear strength $\left(\alpha_{\max }\right)$, which should be function of the strength of a single bond, was equal for all series $(7.3 \mathrm{MPa})$. The coefficients of determination, 
as well as the significance level, are also presented in Table 1 in order to evaluate the predictive ability of the proposed model.

Table1. Optimized variables of the proposed model

\begin{tabular}{lcccccccc}
\hline Catalyst & \multicolumn{4}{c}{ Phosphoric acid } & \multicolumn{4}{c}{ Ammonium sulfate } \\
\hline Temperature & 85 & 95 & 105 & 115 & 85 & 95 & 105 & 115 \\
$t_{0}$ & 419.9 & 235.6 & 138.9 & 66.6 & 259.5 & 157.2 & 113.9 & 31.1 \\
$\lambda$ & 217.8 & 125.8 & 81.9 & 65.2 & 131.7 & 103.7 & 119.2 & 68.5 \\
$R^{2}$ & 0.966 & 0.991 & 0.994 & 0.994 & 0.973 & 0.990 & 0.992 & 0.967 \\
& $\left({ }^{* *}\right)$ & $(* *)$ & $(* *)$ & $\left({ }^{* *}\right)$ & $(* *)$ & $(* *)$ & $\left({ }^{* *}\right)$ & $(* *)$ \\
\hline
\end{tabular}

Significance level $-(* *)=0.1 \%$.

\section{CONCLUSIONS}

ABES apparatus is an excellent technique for bonding evaluation. Shear strength is extremely dependent of the resin load in the glue joint. Increasing the resin load increases the maximum shear strength. However, above $100 \mathrm{~g}$ per square meter, increasing resin load led to an adverse effect on shear strength. The ideal resin load for bonding evaluation is around $100 \mathrm{~g} / \mathrm{m}^{2}$.

The proposed model with three parameters adjusts the experimental data well, supporting that the proposed reactive scheme can represent the bonding development during the resin cure. The model proposed is robust, being an alternative method for "mechanical cure" characterization of wood adhesives.

\section{ACKNOWLEDGMENTS}

This work is co-founded by Fundo Europeu de Desenvolvimento Regional (FEDER)/QREN (E0 formaldehyde project with reference FCOMP010202FEDER005347) under the framework of COMPETE - Programa Operacional Factor de Competitividade (POFC). The authors wish to thank Sonaelndústria PCDM (Mangualde, Portugal) for providing the raw materials needed for this work. Nuno Costa wishes to thank to EuroResinas and FCT/MCTES for Ph.D. grant SFRH/BDE/33655/2009.

\section{REFERENCES}

1. Thoemen, H., Wood-based Panels - An Introduction for Specialists, H. Thoemen, M. Irle, and M. Sernek (Eds.) (Brunel University Press, London, England, 2010).

2. Anonymous, Wood handbook: Wood as an engineering material, General Technical Report FPL-GTR-190, (U.S. Forest Products Laboratory, Department of Agriculture, Forest Service, Forest Products Laboratory, Madison, WI, 2010).

3. Martins, J., Pereira, J., Pinto, B., Coelho, C., and Carvalho, L., Effect of recycled wood on formaldehyde release of particleboard, in COST Action E49 Confer- ence "Measurement and Control of VOC Emission from Wood-Based Panels, (Braunschweig,Germany, 2007).

4. International Agency for Research on Cancer (IARC), Formaldehyde, 2-butox-yethanol and 1tert-butoxypropan-2-ol, IARC Monogr Eval Carcinog Risks Hum, 88, (2006).

5. FormaCare, Wood panels \& formaldehyde, <http://www.formaldehyde-europe. 
org/fileadmin/formaldehyde/PDF/BS.Wood.pdf>, (accessed October 18th 2012).

6. Costa, N., Henriques, A., Pereira, J., Paiva, N., Ferra, J., Cruz, P., Magalhães, F., Martins, J., Mendes, A., and Carvalho, L., Scavengers to reduce formaldehyde emission from wood-based panels, in 2012 IUFRO Conference - Division 5 Forest Products, Lisboa, Portugal (2012).

7. Dunky, M., Int. J. Adhes. Adhes. 18, 95-107 (1998).

8. Pizzi, A., Urea-formaldehyde adhesives, in Handbook of Adhesive Technology, Pizzi and K. Mittal (Eds.) (Marcel Decker, Inc., New York, Basel, Hong Kong, 1994).

9. Athanassiadou, E. and Ohlmeyer, M., Emissions of formaldehyde and VOC from wood-based panels, in COST Action WG3 (E49)-Performance in Use and New Products of Wood Based Composites, M. Fan, M. OhImeyer, M. Irle, W. Haelvoet, E. Athanassiadou, and I. Rochester (Eds.) (Brunel University Press, London, 2009), pp. 219-240.

10. Ferra, J., Henriques, A., Mendes, A., Costa, M., Carvalho, L., and Magalhães, F., J. Appl. Polym. Sci. 123, 1764-1772 (2012).

11. Kumar, R., Han, T., Rozman, H., Daud, W., and Ibrahim, M.,J. Appl. Polym. Sci. 103, 2709-2719 (2007).

12. Costa, N., Amaral, S., Alvim, R., Nogueira, M., Schwanningerand, M., and Rodrigues, J., J. Appl. Polym. Sci. 128, 498-508(2013).

13. Paiva, N., Henriques, A., Cruz, P., Ferra, J., Carvalho, L., and Magalhães, F., J. Appl. Polym. Sci. 124, 2311-2317 (2012).

14. Eom, Y.-G., Kim, J.-S., Kim, S., Kim, J.-A., and Kim, H.-J., Mokchae Konghak 34, $29-41$ (2006).

15. Kim, S., Constr. Build. Mater. 23, 2319-2323 (2009).

16. Kim, S., Kim, H.J., Kim, H., and Lee, H., Macromol. Mater. Eng. 291,1027-1034 (2006).

17. Gunnells, D. and Griffin, K., Catalyst systems, in Resin \& Blending Seminar Proceedings, Portland, Oregon and Charlotte, North Carolina) (1998).

18. Costa, N., Pereira, J., Martins, J., Ferra, J., Cruz, P., Magalhães, F., Mendes, A., and Carvalho, L., Int. J. Adhes. Adhes. 33,56-60(2012).

19. Ferra, J., Mendes, A., Costa, M., Carvalho, L., and Magalhães, F., J. Adhes. Sci. Technol. 24,15351551(2010).

20. Park, B.-D., Kim, Y., Singh, A., and Lim, K.,J. Appl. Polym. Sci. 88, 2677-2687 (2003).

21. Henriques, A., Ferra, J., Cruz, P., Martins, J., Magalhães, F., and Carvalho, L., International Wood Products Journal 3, 64-66 (2013).

22. Henriques, A., Cruz, P., Ferra, J., Martins, J., Magalhães, F., and Carvalho, L., J. Appl. Polym. Sci. 124, 2441-2448 (2012).

23. Soulard, C., Kamoun, C., and Pizzi, A., J. Appl. Polym. Sci. 72, 277-289 (1999).

24. Rammon, R.,Johns, W., Magnuson, J., and Dunker, A., The Journal of Adhesion 19, 115-135 (1986).

25. Carvalho, L., Costa, M., and Costa, C., J. Appl. Polym. Sci. 102, 5977-5987 (2006).

26. Costa, N., Henriques, A., Pereira, J., Paiva, N., Cruz, P., Ferra, J., Magalhães, F., Martins, J., Mendes, A., and Carvalho, L., Kinetic models for cure and bonding strength analyses of UF resins with low formaldehyde emission (in Portuguese), in 6th Congresso Luso-Moçambicano de Engenharia, J. Gomes, C.

António, C. Afonsoand, and A. Matos (Eds.) (Edições INEGI, Maputo, Mozambique, 2011).

27. Tsou, C. T., "Etude de la Cinetique de ReticulationEt D'Hydrolysedes AdhesifsUree-

Formol," Ph.D. Thesis, Universite de Nancy, Nancy, France (1990).

28. Szesztay, M., Laszlohedvig, Z., Kovacsovics, E., and Tudos, F., Holz. Roh. Werkst. 51, 297-300 (1993).

29. Dunky, M., The chemistry of adhesives, in COST Action E13: Wood Adhesion and Glued Products, Working Group 1: Wood Adhesives, State of the art Report, M. Dunky, T. Pizzi, and M. Leemput (Eds.) (Directorate-General for Research, European Commission, 2001).

30. Humphrey, P., Device for testing adhesive bonds, US Patent 5176028 (1993).

31. Martins, J., Coelho, C., Ferra, J., Cruz, P., and Carvalho, L., International Wood Products Journal 3, 31-35(2012).

32. Paiva, N., Ferra, J., Cruz, P., Martins, J., Magalhães, F., and Carvalho, L., Study of the cure of 
aminoresins with very low formaldehyde emission, in Ecowood 2012 - 5th International Conference on Environmentally-Compatible Forest Products, Porto, Portugal(2012).

33. Chowdhury, M. and Humphrey, P., Wood Fiber Sci. 38, 351-358 (2006).

34. Lecourt, M., Pizzi, A., and Humphrey, P., Holz. Roh. Werkst. 61, 75-76 (2003).

35. Jost, M. and Sernek, M., Wood Sci. Technol. 43, 153-166 (2009).

36. Humphrey, P., Outline standard for adhesion dynamics evaluation employing the ABES (Automated Bonding Evaluation System) technique, in International Conference on Wood Adhesives Proceedings (Forest Products Society, Lake Tahoe, Nevada, USA, 2009). 